\title{
APPLICATION OF MODIFIED GASOLINE TO INCREASE ENERGY EFFICIENCY AND ENVIRONMENTAL PARAMETERS OF VEHICLE OPERATION
}

\author{
ELENA MAGARIL ${ }^{1} \&$ ROMEN MAGARIL ${ }^{2}$ \\ ${ }^{1}$ Department of Environmental Economics, Ural Federal University, Russia \\ ${ }^{2}$ Department of Oil and Gas Processing Technology, Tyumen Industrial University, Russia
}

\begin{abstract}
The implementation of the strategy for the transition of mankind to consciously regulated development is inextricably linked with the requirements for reducing the energy and resource intensity of the economy. Automobile transport is one of the main consumers of hydrocarbon fuels, which, with the growth of the global car fleet, inevitably causes negative consequences for the environment, and the environmental load increases, even considering the progress in the quality of motor fuels. A radical change in the structure of the global fleet with the transition to the use of "green" types of fuel and energy is impossible to implement in short order and is not rational from the economic point of view. An urgent task is to search for the diversified approaches using new-generation technologies for the environmentally friendly adaptation of the use of traditional motor fuels and to reduce the energy intensity of the transport process. The aim of the work is to study the possibilities of increasing fuel efficiency and improving cars' environmental performance using gasoline modified by the introduction of a highly effective nano-additive. The tests carried out on the effect of the introduction of the nanoadditive in the conditions of suburban driving demonstrated a decrease in the specific gasoline consumption up to $14.08 \%$. This reduction in fuel consumption is accompanied by a corresponding reduction in emissions of toxic substances and greenhouse gases. It was found that improving the combustion process of the fuel with the introduction of the additive reduced the levels of noise and vibration, thus reducing pollution of the acoustic environment. The use of gasoline modified by the introduction of nano-additives will reduce the energy intensity of the transport process and will contribute to improving the environmental situation.
\end{abstract}

Keywords: energy efficiency of transport, conventional motor fuels, nano-additive, modified gasoline, acoustic pollution, environmental safety of cars.

\section{INTRODUCTION}

A shift to a new technological paradigm is accompanied by a long and complicated period of changes in energy sources. Currently, the problems associated with the use of fossil fuels and rapid depletion of their resource require urgent measures to expand the use of new acceptable and energy-efficient technologies for all industries consuming conventional hydrocarbon fuels. At the present stage, many developed countries, which do not possess significant reserves of hydrocarbon resources, are actively introducing the latest developments in the field of alternative energy, striving to increase their competitiveness and expand their application [1], [2]. Meanwhile, a cardinal change in the structure of world energy consumption cannot be carried out instantly; this process takes a long time. Transport, according to BP assessment [3], is one of the main final consumers of primary energy $(20.6 \%$ in 2020) and the main consumer of liquid petroleum fuels. The US Energy Information Administration [4] forecasts the transport sector's consumption of liquid fuels to amount 59\% of total final consumption by 2050 without changing significantly their share compared to the level of 2018. At the same time, the use of alternative energy and fuels in transport, which currently do not contribute significantly in total energy consumption, will expand in the long term, which will reduce the demand for fossil fuels. According to forecasts, the demand for 
petroleum products within the transport sector will decrease from 94 to $85 \%$ by 2040 [3] and to $82 \%$ by 2050 [4] due to the slow growth in the use of alternative fuels. However, the future diversification of fuel resources in the transport sector does not exclude the need for urgent measures to improve energy efficiency and environmental parameters of using the conventional fuels. This can be achieved by implementation of new technologies that appear in the modern round of scientific and technological progress, including nanotechnologies.

A well-known method to effectively improve the properties of petroleum products is the use of fuel additives introduced into the fuel in small quantities [5]-[9]. The use of nanoadditives to modify the properties of conventional motor fuels can have a much greater effect than the previous-generation additives. It is known that the transition to the nanoscale state significantly changes the reactivity as well as chemical and physical properties of substances. According to studies previously conducted by the authors [10], [11], multifunctional fuel additives must combine the properties of a surfactant and an effective catalyst for redox reactions. The use of the size effect allows application of nanoscale and nanostructured materials in the development of new generation catalysts with larger amount of active metal involved in catalysis due to an increase in the fraction of surface atoms in their total number, which increases their specific activity in comparison with traditional solid state catalysts.

In the present work, the effect of the multifunctional nano-additive for gasoline, developed by the authors, on fuel efficiency and some environmental parameters of vehicle operation was investigated.

\section{MATERIALS AND METHODS}

The tests were carried out using standard gasoline with research octane number (RON) 95 (Lukoil), and the same gasoline modified by the introduction of a surface-active nanoadditive $\left(\mathrm{C}_{12} \mathrm{H}_{25} \quad \mathrm{COO}\right)_{2} \mathrm{X}$, where $\mathrm{X}$ is a catalytically active metal in an optimum concentration of $18 \mathrm{ppm}$ previously determined by the authors [11].

The effect of the introduction of the nano-additive on the fuel efficiency of cars was investigated by conducting road tests of cars on the highway section of $850 \mathrm{~km}$, setting a constant speed of $60 \mathrm{~km} / \mathrm{h}$. Weather conditions during the test were stable. The tests were carried out on Lada Priora and Ford Focus cars. To determine the initial values of the specific consumption of gasoline, 2 runs were conducted on each of the cars using standard gasoline with the measurement of the specific consumption of gasoline at the end of the run. Then, 2 runs were carried out using modified gasoline with the control of fuel consumption. The deviation of the obtained values of specific fuel consumption from the average value in 2 runs for both cars did not exceed $3 \%$.

The effect of the use of modified gasoline on the noise and vibration levels was studied on a VAZ-2106 car engine using a Bruel \& Kjaer sound level meter (Denmark) 2226 No. 1788689 VSV-003 No. 671. Measurements of noise and vibration were carried out at steady state driving conditions. Initially, acoustical oscillations and vibration were measured on a car with using standard gasoline. Then the car was switched to the use of modified gasoline. Noise and vibration levels were measured again after a mileage of $600 \mathrm{~km}$ using modified gasoline.

\section{RESULTS AND DISCUSSION}

The test results of the effect of using the modified gasoline on specific fuel consumption are shown in Fig. 1. The combination of surface-active and catalytic effects of the multifunctional nano-additive provides an effective increase in fuel efficiency of car engines. 


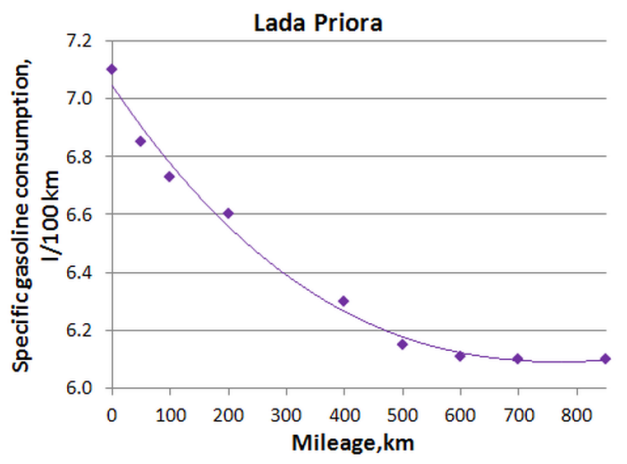

(a)

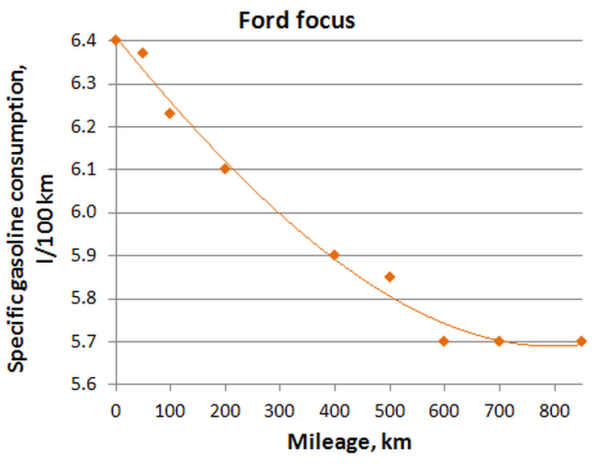

(b)

Figure 1: The effect of the use of modified gasoline on the fuel efficiency of cars. (a) Lada Priora; (b) Ford Focus.

The specific consumption of modified gasoline before the start of the run was taken equal to the specific consumption of standard gasoline obtained in preliminary tests. A much smaller increase in the fuel efficiency in the early stages of the run can be explained by the fact that the initial effect is mainly caused by the surface-active action of the additive, which provides better mixture formation in the engine [8], [12]. A more significant reduction in the specific fuel consumption is possible after eliminating carbon deposits in the engine, which is achieved as a result of the catalytic action of the additive. More time is required to achieve the maximum effect of the nano-additive and eliminate completely carbon deposits in the engine. As the protective-catalytic nanolayer is formed on the working surfaces in the engine, complete cleansing of the engine from carbon deposits is achieved [10], [13], [14], and the decrease in the specific consumption of gasoline reaches its maximum value; after that, the specific consumption does not change. The maximum decrease in specific consumption was achieved after $550-600 \mathrm{~km}$ of mileage on gasoline, modified by the introduction of the nanoadditive. The decrease in specific consumption reached $14.08 \%$ for the Lada Priora car, and $10.94 \%$ for the Ford Focus car, which is higher than those in previous tests [11] (11.3 and $7.8 \%$, respectively). This is explained by the longer mileage which allowed one to achieve the maximum possible effect in increasing fuel efficiency as a result of the use of the fuel modified by the nano-additive, while in previous experiments with a mileage of $420 \mathrm{~km}$ the maximum effect was not achieved.

It should be noted that previous studies [11] also showed that the use of the nano-additive allows the use of gasoline with a reduced octane rating, which is consistent with existing concepts on the influence of carbon deposit on the requirements for the octane number of cars [15]-[17]. Accordingly, a reduction in specific consumption will reduce carbon dioxide emissions. Reducing emissions of toxic substances when using modified fuel should be even more significant, given the previously obtained data [13], [14] on the influence of the prototype nano-additive on the environmental parameters of engines.

Figs 2 and 3 present the results of studies on the effect of the use of gasoline, modified by the introduction of the nano-additive, on acoustic oscillations and vibration in the engine.

The average engine noise reduction was $7.13 \%$ at a speed of $50 \mathrm{~km} / \mathrm{h}$ (3rd gear) and $8.35 \%$ at a speed of $90 \mathrm{~km} / \mathrm{h}$ (4th gear) in the frequency range of 32-8000 Hz. 


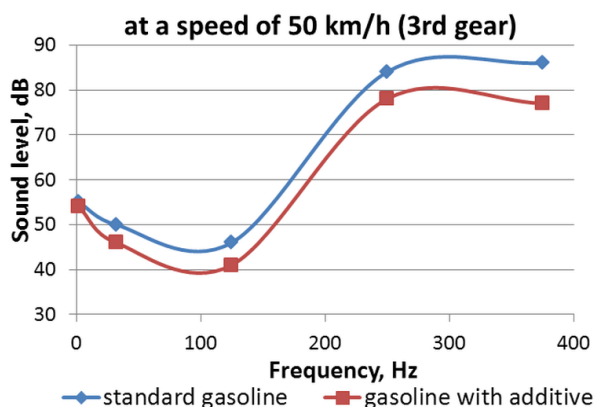

(a)

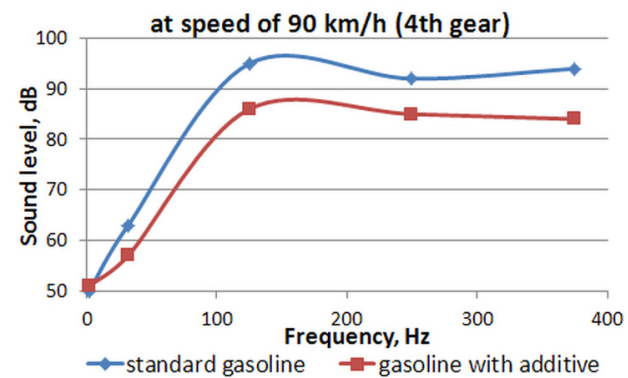

(c)

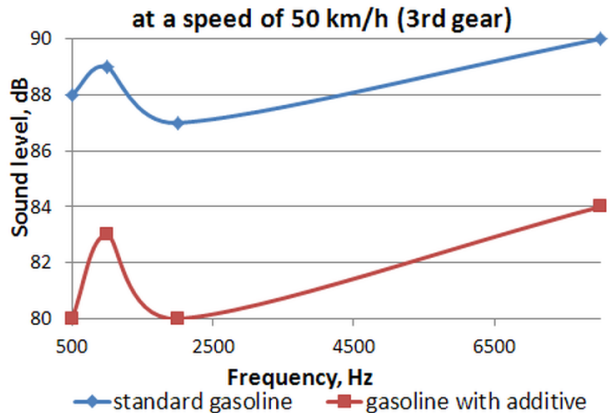

(b)

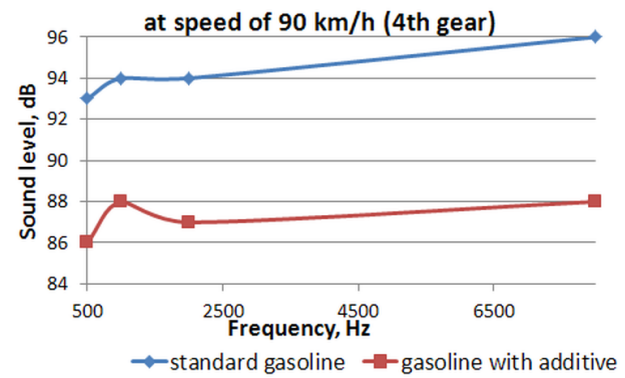

(d)

Figure 2: The effect of using modified gasoline on the change in acoustic oscillations in the engine. (a), (b) Sound level measured at a speed of $50 \mathrm{~km} / \mathrm{h}, 3 \mathrm{rd}$ gear; (c), (d) Sound level measured at a speed of $90 \mathrm{~km} / \mathrm{h}, 4$ th gear.

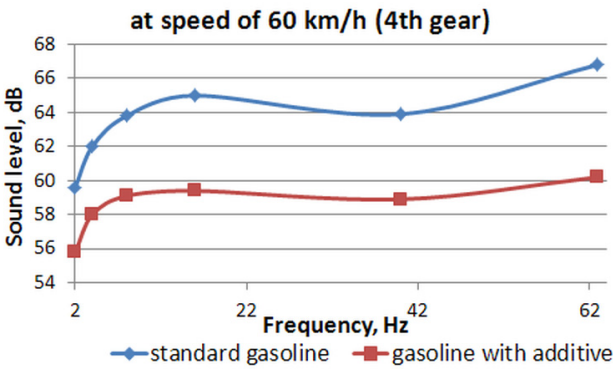

(a)

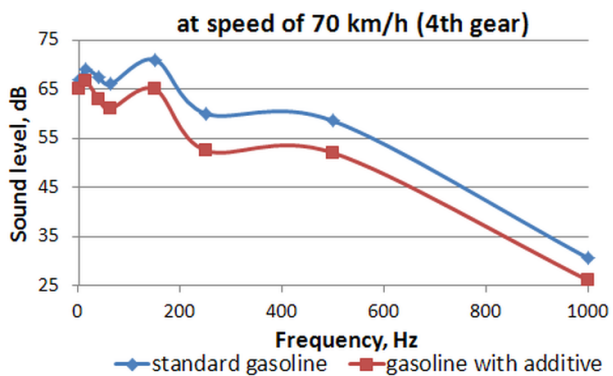

(b)

Figure 3: The effect of using modified gasoline on the change in the vibration level. (a) Vibration level change (total) at a speed of $60 \mathrm{~km} / \mathrm{h}$ (4th gear); (b) Vibration level change (local) at a speed of $70 \mathrm{~km} / \mathrm{h}$ (4th gear).

The more significant reduction in acoustic oscillations achieved in this study compared to that previously obtained by the authors of [11] (6.23 and 6.3\% at the indicated speeds) was due to the fact that in earlier experiments the measurements of the noise level after the introduction of the nano-additive were carried out after a smaller mileage on modified fuel 
then as in this experiment with the mileage of $600 \mathrm{~km}$. The greater mileage provides a greater degree of elimination of carbon deposits due to the catalytic effect of the nano-additive. This improves to a greater extent smoothness of fuel combustion and reduces acoustic oscillations in the engine.

The measurements of the vibration level, as demonstrated in Fig. 3, confirmed the effectiveness of the use of modified gasoline also regarding the influence on the vibration effects. A decrease in vibration (total) at a speed of $60 \mathrm{~km} / \mathrm{h}$ (4th gear) and in a range of frequencies from 2 to $63 \mathrm{~Hz}$ averaged $7.8 \%$. Local vibration at a speed of $70 \mathrm{~km} / \mathrm{h}$ (4th gear) in the frequency range of $16-1000 \mathrm{~Hz}$ decreased at an average by $8.11 \%$.

Automobile transport significantly contributes not only to air pollution by emissions of toxic substances and greenhouse gases, but also to the pollution of the acoustic environment due to excessive noise and vibration during car operation. The use of modified gasoline provides great opportunity for substantial reduction in acoustic pollution and is undoubtedly significant from the point of view of improving the urban environment and reducing the health effects of vehicle owners and passengers.

\section{CONCLUSIONS}

The use of gasoline modified by the introduction of the nano-additive developed by the authors can significantly increase the fuel efficiency of engines, which, when widely introduced, will significantly slow down the rate of petroleum reserves reduction. At the same time, reduction both in emissions of toxic combustion products of gasoline and greenhouse gases and acoustic pollution will contribute to improvement of environmental health. In the future, it is advisable to conduct a study of the dependence of the effectiveness of the proposed technology on the car age. It can be expected that for cars with longer operation the effect of the nano-additive on fuel consumption will differ from that for new car engines due to a larger layer of carbon deposits in the engine. The use of gasolines modified by the nanoadditive allows achieving a serious environmental and economic effect and increasing the energy efficiency of car operation at the present stage, when the share of alternative fuels and energy in the consumption structure of the global fleet remains low.

\section{ACKNOWLEDGEMENT}

This research was supported by Act 211 Government of the Russian Federation, contract no. 02.A03.21.0006.

\section{REFERENCES}

[1] Schiavon, M., Rada, E.C., Cioca, L.-I., Torretta, V. \& Ragazzi, M., Environmental and managerial advantages of treatment plants exploiting biogas from food waste. International Journal of Energy Production and Management, 3(4), pp. 292-306, 2018.

[2] Genon, G., Panepinto, D. \& Viggiano, F., Sustainability in energy production. International Journal of Energy Production and Management, 1(1), pp. 16-32, 2016.

[3] BP Energy Outlook, 2019. www.bp.com/en/global/corporate/energy-economics/ energy-outlook.html. Accessed on: 20 Feb. 2020.

[4] International Energy Outlook 2019 with Projections to 2050. US Energy Information Administration, 2019. www.eia.gov/ieo. Accessed on: 20 Feb. 2020.

[5] Danilov, A.M., Development and use of fuel additives during 2006-2010. Chemistry and Technology of Fuels and Oils, 47, pp. 470-484, 2012.

[6] Srivastava, S.P. \& Hancsók, J. Fuels and Fuel-Additives, John Wiley \& Sons Inc.: Hoboken, NJ, USA, 2014. 
[7] Priyadarshi, D., Paul, K.K. \& Pradhan, S., Impacts of biodiesel, fuel additive, and injection pressure on engine emission and performance. Journal of Energy Engineering, 145, 04019006, 2019.

[8] Magaril, E. \& Magaril, R., Improving the environmental and performance characteristics of vehicles by introducing the surfactant additive into gasoline. Environmental Science and Pollution Research, 23, pp. 17049-17057, 2016.

[9] Al-Kayiem, H.H., Wahhab, H.A.A., Magaril, E. \& Aziz, A.R.A., Performance and emissions investigation of a single cylinder diesel engine using enhanced blend biodiesel by nanoparticles. AIP Conference Proceedings, 2035, 020008, 2018.

[10] Magaril, E. \& Magaril, R. Fuel quality: Challenges to the sustainable development of automobile transport and approach to solution. E3S Web of Conferences, 6, 03001, 2016.

[11] Magaril, E., Magaril, R., Al-Kayiem, H.H., Skvortsova, E., Anisimov, I. \& Rada, E.C., Investigation on the possibility of increasing the environmental safety and fuel efficiency of vehicles by means of gasoline nano-additive. Sustainability (Switzerland), 11(7), P. 2165, 2019.

[12] Magaril, E. \& Magaril, R., Impact of surfactants in micro concentrations on certain properties of organic liquids as a basis for improving some oil-and-gas industry processes and properties of gasoline. Colloids and Surfaces A: Physicochemical and Engineering Aspects, 529, pp. 733-738, 2017.

[13] Magaril, E., The influence of carbonization elimination on the environmental safety and efficiency of vehicle operation. International Journal of Sustainable Development and Planning, 8(2), pp. 231-245, 2013.

[14] Magaril, E., Carbon-free gasoline engine operation. International Journal of Sustainable Development and Planning, 10, pp. 100-108, 2015.

[15] Magaril, E.R., Magaril, R.Z. \& Bamburov, V.G., Specific features of combustion in gasoline-driven internal combustion engines. Combustion, Explosion and Shock Waves, 50(1), pp. 75-79, 2014.

[16] Gruse, W.A. \& Stevens, D.R., Chemical Technology of Petroleum, McGraw-Hill: New York, 1960.

[17] Gureev, A.A. \& Azev, V.S. Car Gasolines. Properties and Application, Neft: Moscow, 1966 [in Russian]. 